\title{
A Review on Non-Destructive Test and Retrofitting
}

\author{
Akshay K. Doble ${ }^{1}$, Dr. Prashant Y. Pawade 2 , Dr. Rashmi Bharatey ${ }^{3}$ \\ ${ }^{1}$ Research Scholar,Department of Civil Engineering, G.H. Raisoni College of Engineering, Nagpur, Maharashtra, India \\ ${ }^{2}$ Professor, Department of Civil Engineering, G.H. Raisoni College of Engineering, Nagpur, Maharashtra, India \\ ${ }^{3}$ Assistant Professor, Department of Civil Engineering, G.H. Raisoni College of Engineering, Nagpur, Maharashtra, India
}

\begin{abstract}
Deterioration of Reinforced Concrete Structure made an alarming situation for researchers and students for specializing in the sturdiness affecting parameters along side crushing strength, various uncontrollable parameters like environmental or exposure situations are equally important for the service existence of structures. Rusting of reinforcement in strengthened concrete diminishes the provider existence and exacerbates concrete structures causing early stage failure of structures. Therefore, assessing present situation of reinforced concrete structure is essential for planning, repairing and replacing of structure.
\end{abstract}

Keywords:- Compressive strength, Durability, Non-Destructive Test, Service life, Strengthening

\section{INTRODUCTION}

A great test of RC structures is usually is done by testing standard models. Therefore, live preparation is required to determine the strength of the concrete examination of prepared samples. The standard test procedure gives the idea of potential concrete strength. However, the results of the standard test may not be the same as the actual test concrete strength as compression and curing systems the in situ and standard method of application is very different. Accordingly, non-destructive tests are widely used assess the strength of RC structures. Rather, as a name indicates that non-destructive tests do no damage or does not damage the concrete and affect the performance of the structure. These techniques are also useful for fine-tuning. Construction planning is a big task in construction projects, which need to know strength of concrete structures to assess removal of Formwork time, pressure or release time for strings in pre-stressed members, the loading time for the system, time to open up post-tensional elements or structure safe service. There are a variety of non-destructive methods available to assess concrete strength of structures.

A method for identifying non-destructive testing (NDT) asymmetric parameters of indirectly hardened concrete without loading the sample until the strength, durability and other elastic properties fail. These methods are based on some physical and chemical properties related to the strength and other properties of the material like concrete. These methods have great potential to be part of one such technology. There is an array of advanced NDT methods launched and will be available for study and evaluation of different parameters. In the last decade, there has been non-destructive testing (NDT) and has achieved an important place in the quality assurance of evaluation of hardened concrete and existing concrete structure about their strength \& durability. Also NDT tests are easy to perform and instrumental. 
Basically, it is not the analysis and clarification of test data because simple, concrete is a complex material, that is why engineers warn that the test is an interpretation of the data and always be handled by professionals trained in NDT rather than through the technicians who perform the tests. Non Destructive tests used to determine the compressive strength of interaction between concrete, measured, mechanical or otherwise physical and strength are usually not special. This is what arises from the diversity in the relationships between measured attribute and the factors that make up the concrete strength, among others: cement contents, gravel type, bonding between cement: paste and gravel and water-cement ratio.

\section{LITERATURE REVIEW}

Many researchers have used different NDT devices to assess the condition of RC structures.

Malkin et al. (2018), Precise Non-destructive estimation of engineering structures using Ultrasonic immersion imaging requires accurate representation in the surface of the structure. In this research, the relationship between surface geometry, surface measurement error Ultrasonic Ranges and Total Focusing Method (TFM) and how it affects the ability to paint a feature. The component was investigated. Shaped surfaces sinusoids that cover a set of surface wavelengths and amplitudes are studied. It can also be observed that it is very poor. The results are achieved if the surface gradient is excessively steep.

S. U. Biraris(2017) told that auxiliary review is a general well being and execution registration of structures .It is imperative to the structure for checking its security and they have no hazard. This is procedure of examinations of structure \& this procedure proposes a suitable fixes \& retrofitting measures required for the structures for performing better in its administration life basic review is a significant instrument to know the genuine well being condition of the old structures.

J. Bhattacharjee (2016) says the development material for the most part strengthened cement is being utilized broadly for different kinds of development ventures. Be that as it may, the decay of Reinforced Concrete structures is perceived as a noteworthy issue around the world. Aside from requiring standard upkeep, numerous structures require broad Repair, Rehabilitation \&Retrofitting. Over some undefined time frame, as these structures become more seasoned, we find in them certain corruption or decay with resultant misery showed through breaking, parting, delaminating, consumption and so on. Such disintegrated structures may be restored by using various types of admixtures and present day fix materials. The paper draws out the current situation with solid structures and the significant zones where improvement is required during its administration life organize for manageable advancement and additionally the technique for completing Repair, Rehabilitation and Retrofitting. This has been gotten subtleties in the paper alongside Case contemplates, where the Author of this paper was legitimately engaged with arranging and execution of the employments.

Mandal et al. (2016). In their research, the destructive test of cementitious stabilized materials were studied using UPV by Flexural strength and flexural modulus tests were performed on CSMs and their constraint modulus observed. Effect of compression, curing time and the amount of the binder is estimated. The result shows that the p-wave, as the density decreases the velocity decreases, while the $\mathrm{P}$-wave speed increases with increasing the curing time and binder amount.

K. R. Villaitramani (2014) told that urbanization is the quick deluge of individuals moving to urban areas. 
The United Nations has anticipated that upto 2050, $64.1 \% \& 85.9 \%$ of the creating \& created world separately can be urbanized. With restricted assets of work, time and account, ghettos around the globe keep on developing in size in appalling conditions for people. Construction of houses, an advancement which can possibly address ecological and maintainability worries at a fast pace, automates the development procedure, empowering mass production of moderate houses. This paper examines the instance in Mumbai, A city of greatest ghetto populace thickness on the planet, where construction can be a promising answer for lodging shortage.

Wang et al. (2014), non-detrimental test techniques are more economical and time-efficient as in comparison to detrimental tests; one major disadvantage is that they're no longer very regular when the check consequences are exercised to estimate the concrete compressive energy. For rebound hammer tests, it is found that concrete compressive electricity reviews have a mean of over $22 \%$ mean absolute error while it's far compared to the "real" compressive electricity assessed thru negative tests.

Park et al. (2014) discovered that there may be more strength absorption because of decrease rebound value. In the case of the concrete compressive power check, low energy and low stiffness concrete will even yield a decrease rebound value.

B. Dadasaheb(2013) says numerous places of the nation have endured tremor in most recent three decades. In costal places of South India confronted Tsunami. In initial three seismic tremors it was discovered that a considerable lot of harmed structures were work in non-built stone work methods. Unreinforced brick work structures are the most powerless during a seismic tremor. Typically they are intended for vertical burdens and since brick work has satisfactory compressive quality, the structures carry on well as long as the heaps are vertical. At the point when such a workmanship structure is exposed to horizontal inertial burdens during a seismic tremor, the dividers create shear and flexural stresses. The quality of workmanship under these conditions frequently relies upon the bond among block and concrete (or stone and mortar), which is very poor. This bond is additionally regularly exceptionally poor when lime mortars or mud mortars are utilized. A brick work divider can likewise experience disappointment in-plane shear, if the inertial powers are in the plane of the divider. Shear disappointment as askew breaks is seen because of this. Be that as it may, cataclysmic breakdown occur when the divider encounters out-of-plane flexure. This can cut down a rooftop and cause more harm. Workmanship structures with light rooftops, for example, tiled rooftops are progressively defenceless against out-of-plane vibrations since the top edge can experience enormous misshapenness. It is constantly helpful to examine the conduct of stone work structures after a seismic tremor, in order to distinguish any insufficiencies in quake safe plan. Considering kinds of brick work development, their presentation and disappointment examples helps in improving the structure and enumerating viewpoints.

Breccolotti et al. (2013) proposed two formulas based totally at the thickness of the carbonated concrete cowl and on the power of the concrete itself. The formulas have been determined using finite detail modeling. Results from finite detail modeling confirmed an amazing settlement with experimental outcomes.

Liang et al. (2013) examined the predicted carbonation life of an present concrete viaduct/bridge in the indices. The outcomes showed that each the systems were serviceable and reliable evaluating the 
initiation time calculated the usage of Fick's second law and other techniques.

Singh and Kotiyal (2013). A relationship between experimentally obtained energy and forecasted power by using the version has been presented through NDT are the ones that can be used to calculate the electricity with out destructive the shape. In this studies paper, the compressive power of concrete is forecasted with the aid of the usage of Artificial Neural Network. The forecasted strength was in comparison with the experimentally acquired actual compressive electricity of concrete and equations are advanced for distinctive models. In addition to this, the relation has been evolved the usage of two NDT techniques for calculation of energy by way of regression analysis.

S. Sorace and G. Terenzi (2013)found that the plan investigation of a progressed seismic retrofit arrangement of a low-ascent fortified solid structure, comprising in the establishment of a dissipative propping framework consolidating pressurized liquid gooey spring-dampers as latent defensive gadgets. This definite application speaks to the last phase of the exploration exercises completed by the creators on this insurance innovation, likewise inside a few universal Research Projects. The basic qualities of the contextual analysis building make it illustrative of a huge supply of comparative structures planned with before Technical Standards releases, in Italy \& in other European seismic-inclined nations. The mechanical parameters, measurements, formats and areas chose for the establishing components of the framework, and the exhibition appraisal investigations in unique and restored conditions did by a full non-direct powerful approach, are introduced. The consequences of the investigations demonstrate a wonderful upgrade of the seismic reaction limits of the structure, which permits arriving at the superior levels proposed in the retrofit plan.

Hannachi \& Guetteche (2012) used rebound hammer and ultrasonic pulse velocity methods to determine the concrete nice through regression analysis models among compressive strength of in situ concrete at the current shape and the values of the nondestructive take a look at. The combined method has been used and equations are derived the use of statistical analysis to estimate the compressive energy of concrete on site. The reliability of the approach for prediction of the strength has been mentioned for a case study.

Sharma and Mukharjee (2011) calculated the corrosion rate the usage of ultrasonic guided waves in bars at exclusive levels in exclusive surroundings. In the prevailing study, the RC beam is fashioned and the corrosion price in oxide and chloride surroundings are checked independently, the variation within the corrosion rate is related correctly to the combination of the guided waves. More the corrosion charge extra will be the possibility of wear and tear. Ultrasonic take a look at outcomes interrelated with a adverse test.

Sangoju et al. (2011) studied corrosion caused by interference of chloride ions in cracked OPC and PPC at distinct w/c ratios by means of using a U-shaped pattern with cracks below flexural load. The pattern is supplied with reinforcement of $12 \mathrm{~mm}$ rebars with a clear cover of $20 \mathrm{~mm}$. quantity of corrosion is calculated by chloride ion penetrability, PPC sorptivity, half mobile potential, resistivity, general charge passed, and galvanometric weight loss. However, this study concludes that the PPC performs a better and massive role than OPC in each the conditions i.E. Pre-cracked and uncracked when they are kept in a chloride rich environment. 
Chloride ion penetration is around 3 times lesser in case of PPC, PPC indicating advanced performance. Half cell technique confirms that PPC has a higher resistance to corrosion.

A. Seth et.al. (2004), pointed the reasons of big scale disaster effect of bhuj earthquake on 26th Jan 2001 as loss of awareness, negligence in following the IS code provisions, by means of the owners, engineers, executors, and implementers. Hence, they state the road of rectification of identified lacunas were to spread understanding about the cause of disastrous impact in public domain via all types of medias, teach the engineers inside the field of method of seismic resistivity techniques and rigorous implementation of specs via concern authorities. They have taken the inventory in situation.

C.R.V. Murty, et. al. (2004) tested the brick masonry structures with precast R.C. Roofing for the purpose of strengthening it. The collapse may be attributed to out-of-plane, in-plane. And incorrect connection between slab / roof with masonry walls. Their findings are dual lintel belt along with vertical nook reinforcement, and right anchorage among slab /roof though provide better seismic resistance as compared to traditional restore methods. They opine that, this device is at risk of sturdy horizontal and vertical floor motions.

G. Ozcebe (2004) mentioned that escalated trial research did for a considerable length of time demonstrated that fortifying of fortified solid $(\mathrm{R} / \mathrm{C})$ outlines by presenting $\mathrm{R} / \mathrm{C}$ infills to the chose sounds in the two bearings is a powerful strategy for the recovery of harmed structures. Be that as it may, this system requires departure of the structure for a while; accordingly its appropriateness in the recovery of the current structures, which are at present being used, is neither doable nor commonsense. Perceptions of poor structure execution after the ongoing quakes in
Turkey and somewhere else and the gigantic existing structure stocks require earnest improvement of creative fortifying systems, which would not interfere with the utilization of the structure during recovery. A trial study was started at the METU Structural Mechanics Laboratory, which intended to grow such reinforcing methods. In this investigation, it was proposed to change over the non load bearing existing brick work dividers and segments into auxiliary components which would shape another horizontal burden opposing framework by reinforcing them with CFRP textures and coordinating them with the current basic framework. In this specific circumstance, 1/3 scaled 2-story 1-inlet fortified solid edges were tried. The edge of the test examples was definite to incorporate the basic inadequacies of the structures in Turkey. All together seven examples were tried. The plan of the CFRP layers, the measure of CFRP utilized, the safe haven of CFRP texture to the divider and the casing components were the real parameters explored. This paper abridges the tests did to build up an effective reinforcing technique for existing structures by the use of CFRP textures to the empty earth tile infills.

M. Joseph et. al. (1997), gave their opinion that during high upward thrust buildings, reliance only on the inertia force developed through roof or top stories, as design criteria might be underestimation. Therefore authors studied. " Acceleration displacement response spectrum (ADRS) format. They carried out dual analytical experimental shocking table study and recorded the seismic deficiencies incorporated and tabulated the results. A retrofitted model was examined with identical parameters and effects had been tabulated. They concluded that Using ADRS format, assessment of diverse proposed seismic retrofitting schemes can be done, as on this case look at, for relative development in electricity and deformation demands and capacities of unique and 
modified structure. Thus one can ascertain the quality suitable technique for adoption.

\section{CONCLUSION}

From the above literature review, it has been mentioned that to get compressive power of present concrete elements. Rebound hammer and UPV techniques are applied by numerous researchers. It has been located that there is a requirement for an insitu testing technique of concrete for figuring out the fine and elements influencing the performance of existing structures. Different systems require special retrofitting techniques depending upon the type and residences of the structure. Some require the procedure of jacketing, whereas some require the method of CFRP wrapping to increase the electricity and decrease the corrosion of metal and the durability of concrete. For seismic structure, a few excessive cease retrofitting such as bracing and bracketing also required. Retrofit not use boom the lifestyles of the structure but it additionally imparts the energy and decreases the degradation of the structural embers.

\section{REFERENCES}

[1]. IS 456:2000 "PLAIN AND REINFORCED CONCRETE- CODE OF PRACTICE"

[2]. IS 875:2015“CODE OF PRACTICE FOR DESIGN LOAD (OTHER THAN EARTHQUAKE) FOR BUILDING AND STRUCTURES. PART I : DEAD LOAD -UNIT WEIGHT OF BUILDING MATERIAL AND STORED MATERIAL."

[3]. IS 875:2015“CODE OF PRACTICE FOR DESIGN LOAD (OTHER THAN EARTHQUAKE) FOR BUILDING AND STRUCTURES. PART II :IMPOSED LOAD.”

[4]. IS 1893:2016“CRITERIA FOR EARTHQUAKE RESISTANT DESIGN OF STRUCTURE.”
[5]. IS 13920:2016“DUCTILE DETAILING OF REINFORCED CONCRETE STRUCTURES SUBJECTED TO SEISMIC FORCES - CODE OF PRACTICE."

[6]. R. Malkin, A. Franklin, R. Bevan. M. Mongelli, H. Kikura, B. Drinkwater, "Surface reconstruction accuracy using ultrasonic arrays: Application to non-destructive testing”. NDT \& E International., 12 March 2018.

[7]. Swapnil U Biraris "STRUCTURAL AUDIT OF OLD STRUCTURES" International Journal of Engineering Trends and Technology (IJETT) Volume-43 Number-3 -January 2017

[8]. KirtikaGupta , Abhishek Kumar,, “'REVIEW PAPER ON SEISMIC RETROFITTING OF STRUCTURES," International Research Journal of Engineering and Technology Volume: 04 Issue: 04 | Apr -2017

[9]. J. Bhattacharjee "REPAIR, REHABILITATION \&RETROFITTING OF RCC FOR SUSTAINABLE DEVELOPMENT WITH CASE STUDIES" Civil Engineering and Urban Planning: An International Journal (CiVEJ) Vol.3, No.2, June 2016

[10]. T. Mandal, J. Tinjum, T. Edil, “Non-Destructive Testing Of Cementitiously Stabilized Materials Using Ultrasonic Pulse Velocity Test, "Transportation Geotechnics"., Volume 6, March 2016, Pages 97-107.

[11]. Krish R. Villaitramani” PREFABRICATED CONSTRUCTION FOR MASS HOUSING IN MUMBAI" International Journal of Innovative Research in Advanced Engineering (IJIRAE) ISSN: 2349-2163 Volume 1 Issue 9 (October 2014)

[12]. Wang, Y.R.; Kuo, W.T.; Lu, S.S.; Shih, Y.F.; Wei, S.S. Applying support vector machines in rebound hammer test. Adv. Mater. Res. 2014, 853, 600-604.

[13]. Park, S.; Kim, J.; Shin, E.; Han, S. Compressive strength evaluation of underwater concrete 
structures integrating the combination of Rebound Hardness and Ultrasonic Pulse Velocity Methods with artificial neural networks. Int. J. Civil Environ. Struct. Constr. Architect. Eng. 2014, 8, 17-21.

[14]. Bhavar Dadasaheb "Retrofitting of Existing RCC Buildings by Method of Jacketing” Vol. 1, Issue: 5, June: 2013 (IJRMEET) ISSN: 2320-6586.

[15]. M. Breccolotti, M. Bonfigli,. M. Materazzi "Influence of carbonation depth on concrete strength evaluation carried out using the SonReb method". NDT \& E International. 59:96-104 • October 2013.

[16]. M. Liang, R. Huang, S. Fang "Carbonation service life prediction of existing concrete viaduct/bridge using timedependent reliability analysis". Journal of Marine Science and Technology, Vol. 21, No. 1, pp. 94-104 (2013) Carbonation service life prediction of existing concrete viaduct/bridge using time-dependent reliability analysis.

[17]. V.P. Singh, Y.C. Kotiyal, "Prediction of Compressive Strength Using Artificial Neural Network," International Journal of Civil, Structural, Construction and Architectural Engineering Vol:7, No:12, 2013.

[18]. S. Sorace and G. Terenzi "ADVANCED SEISMIC RETROFIT OF A LOW-RISE R/C BUILDING" IACSIT International Journal of Engineering and Technology, Vol. 5, No. 3, June 2013

[19]. Hannachi and M. N. Guetteche, "Application of the Combined Method for Evaluating the Compressive Strength of Concrete on Site," Open Journal of Civil Engineering, 2012, 2, 1621.

[20]. Sharma S. and Mukherjee A. (2011). "Monitoring corrosion in oxide and chloride environments using ultrasonic guided waves". Journal of Materials in Civil Engineering, 23(2), 207-211.
[21]. Sangoju; R. Gettu; B. H. Bharatkumar; and M. Neelamegam, "Chloride-Induced Corrosion of Steel in Cracked OPC and PPC Concretes: Experimental Study," Journal of Materials in Civil Engineering, Vol. 23, No. 7, July 1, 2011.

[22]. Alpa Seth, Sudhir K. Jain, THIRUPPUGAZH V."Earthquake Capacity Building and Risk reduction Majoures in Gujarat Post 2001 Earthquake". 13th WCEE Aug 2004, P. No. 2018

[23]. Murty C.R.V., Datta Jayanta, Agrawal S.K. (EE\&EV)V.3 no.2 Dec 2004."Twin Lintel Belt in Steel for Seismic Strengthening of Brick Masnory Buildings".

[24]. Guney Ozcebe "REHABILITATION OF EXISTING REINFORCED CONCRETE STRUCTURES USING CFRP FABRICS" 13th World Conference on Earthquake Engineering Vancouver, B.C., Canada August 1-6, 2004 Paper No. 1393

[25]. Joseph M., Barcci, Sashi K. Kunnath JSE Jan. (1997) paper no. 10373,"Seismic Performance and Retrofit Evaluation of RCC Structure".

[26]. Handbook on repairs and rehabilitation of RC buildings CPWD

\section{Cite this article as :}

Akshay K. Doble, Dr. Prashant Y. Pawade, Dr. Rashmi Bharatey, "A Review On Non-Destructive Test And Retrofitting", International Journal of Scientific Research in Science and Technology (IJSRST), Online ISSN : 2395-602X, Print ISSN : 23956011, Volume 7 Issue 2, pp. 551-557, March-April 2020. Available at doi

https://doi.org/10.32628/IJSRST2072102

Journal URL : http://ijsrst.com/IJSRST2072102 